\title{
La Terapia Gestalt y la presencia terapéutica de Fritz Perls: una entrevista a Claudio Naranjo
}

Gestalt Therapy and the Therapeuthic Presence of Fritz Perls: an Interview with Cuadro Naranjo

\author{
IváN RAMíREZ CALDERÓN \\ Escuela de Gestalt Claudio Naranjo \\ Transformación Humana, Colombia
}

RESUMEN

Como testigo y partícipe de excepción en el origen y desarrollo de la Terapia Gestalt, en esta entrevista, Claudio Naranjo considera las características de esta forma de terapia, a partir de su trabajo y de su encuentro personal con el hombre y la figura terapéutica de Fritz Perls. A lo largo de la entrevista se establece la base experiencial y los elementos del cambio terapéutico, junto con la actitud terapéutica y la concepción holística de la persona; además, se destacan los contrastes entre la Psicología académica, la dimensión espiritual del ser humano y la intuición del terapeuta en la relación de ayuda. Palabras clave autores

Psicología, Psicología Humanista, Terapia Gestalt, Fritz Perls.

Palabras clave descriptores

Claudio Naranjo-Entrevista, Terapia Gestalt-Fritz Perls, Terapia Gestalt-Historia.

\section{A B S T R A C T}

As exceptional witness and participant in the origin and development of the Gestalt therapy, Claudio Naranjo considers in this interview the characteristics of this form of therapy, doing so from his work and his personal encounter with the man and the therapeutic figure of Fritz Perls. In the interview the experiential base and the therapeutic change elements are established, along with the therapeutic attitude, and the holistic conception of the person; also, the contrasts among academic psychology, the spiritual dimension of human beings, and the therapist's intuition in the help relationship are highlighted.

Key words author

Psychology, Humanistic Psychology, Gestalt Therapy, Fritz Perls.

Key words plus

Claudio Naranjo-Interview, Gestalt Therapy-Fritz Perls, Gestalt Therapy-History. 


\section{En relación con Claudio Naranjo}

Resumir la trayectoria de Claudio Naranjo resulta difícil, en especial si se quiere hacer con una óptica lineal. Más apropiado es quizá suponer que tanto la persona como la obra están tan íntimamente ligadas que es mejor considerarlas interrelacionadas como una totalidad, más aún si se entiende que su trayectoria es singular en cuanto que abona e influye en el terreno donde se interceptan las tradiciones espirituales y el conocimiento académico de la intimidad psicológica del ser humano. Ya que su formación es multidisciplinar y sus intereses variados, se presentarán aquí los aspectos de su trayectoria que quizá sirvan más a la intención de distinguir su perfil.

Claudio Naranjo hizo estudios en Música y Filosofía y es Médico de la Universidad de Chile. Se formó como psiquiatra bajo la supervisión de Ignacio Matte-Blanco; fue profesor de Psicología del Arte, de Psiquiatría Social, y además Director del Centro de Estudios de Antropología Médica y Director de la Clínica Psiquiátrica de esa misma Universidad.

Realizó estancias de aprendizaje e investigación en la Universidad de Harvard con Gordon Allport, en la Universidad de Illinois con Raymond B. Cattel, y en el Instituto de Evaluación e Investigación de la Personalidad en la Universidad de Berkeley. Establecido en Estados Unidos, pasa a ser parte del grupo que se formó en el primer periodo del Instituto Esalen, donde aprende Terapia Gestalt con Frtitz Perls y es designado por aquel como uno de sus tres sucesores. Igualmente, enseñó Religión Comparada en el Instituto de Estudios Asiáticos de California, Psicología Humanista en la Universidad de California en Santa Cruz, y Meditación en el Instituto Nyngma de Berkeley. Por otro lado, su inquietud vital no necesariamente se relacionaba siempre con el mundo intelectual, así que buscó enseñanzas de diferentes maestros como Swami Muktananda, Idries Shah, Oscar Ichazo, Suleyman Dede, S.S. el Karmapa XVI y Tarthang Tulku Rinpoché. Del contacto con estas personas y de su trabajo investigativo sobre las dimensiones de la personalidad, surge su elaboración integrada de los tipos caracterológicos a través del Eneagrama, elaboración que hoy es la más reconocida.
En los años setenta, da origen al Programa SAT, el cual paulatinamente crece y se convierte en una escuela holística que integra tanto las tradiciones espirituales como lo disciplinar y psicoterapéutico. El SAT, originalmente, fue concebido para la formación de psicoterapeutas y hoy se extiende también a la formación personal de otros profesionales de la salud y la educación. Sus actividades comenzaron en Estados Unidos, España, Italia, Alemania y hoy también se desarrollan en México, Colombia, Brasil, Chile, entre otros países. A partir de los años noventa, ha dirigido también su atención a la estructura de la educación en varios países del mundo, y ha trabajado en promover en esta estructura una actitud compasiva, de transformación individual y responsabilidad social.

Ha publicado los libros The Unfolding of Man (1969), The One Quest (1972), On the Psychology of Meditation (1971), The Healing Journey (1975), La vieja y novísima Gestalt: actitud y práctica (1990), La agonía del patriarcado (1993), Gestalt sin fronteras (1995), Entre meditación y psicoterapia (1999), Carácter y neurosis (1996), El Eneagrama de la sociedad (2000), Cantos del despertar (2002), Autoconocimiento Transformador, Los eneatipos en la vida, la literatura y la clínica (1999), Cambiar la educación para cambiar el mundo (2002), Gestalt de vanguardia (2003), Sanar la civilización (2009), entre otros. Igualmente, tiene más de 100 artículos publicados en ediciones de revistas de diversos campos como la Neuropsiquiatría, la Psicoterapia y la Espiritualidad.

Actualmente, es Miembro Honorario de la Asociación Colombiana de Terapia Gestalt (ACTG); Miembro del Concejo del Instituto para la Investigación Cultural de Londres; Miembro del Club de Roma en Estados Unidos; Miembro Honorario de la Asociación Internacional de Gestalt; Doctor Honoris Causa en Ciencias de la Formación Primaria de la Universidad de Udine en Italia, entre otras distinciones y participaciones.

\section{La Entrevista}

La entrevista se realizó con motivo de la reciente visita de Claudio Naranjo a Colombia. La grabación, 
la transcripción y las revisiones fueron realizadas en Bogotá. Iván Ramírez Calderón, entrevistador.

- I R C: Quiero comenzar por comentar que en otros momentos has dicho que la Terapia Gestalt es un enfoque singular de terapia, porque pone la atención más sobre la intuición o sobre la comprensión viva y directa que se hace de la relación de ayuda, que sobre los presupuestos teóricos (Naranjo, 1990). ¿Qué principios soportan un enfoque de terapia como este?

Claudio Naranjo: Yo creo que a Perls le hubiera gustado decir que ninguno. Él tuvo una época, en los años cincuenta cuando estaba en Nueva York rodeado de una serie de colaboradores talentosos, como Laura Perls, Paul Goodman y otros, donde hacía algo en terapia que no venía de su formación psicoanalítica; él era, o había sido, un psicoanalista que fue derivando hacia otras maneras de hacer terapia, y lo fue haciendo en forma intuitiva. Entonces, pasó por una época en que sintió que lo que él hacía, el trabajo que él transmitía, no podría mostrarse al mundo sin una teoría, porque estaba pasando la psicoterapia por una época muy deseosa, muy sedienta de teoría. No se consideraba válido lo que no tuviera explicaciones, y eso porque el psicoanálisis era un movimiento muy intelectual, porque Freud era un maniático de la teoría, era un teórico, tal vez más que un terapeuta incluso; entonces allí pagó un dinero que es ridículamente poco, visto por nuestros ojos de hoy, le pagó 500 dólares que había ahorrado, no era mucha la plata que tenia, a Paul Goodman, para que Paul Goodman le confeccionase una teoría. Y Paul Goodman es un hombre más intelectual, él ha conocido el mundo de la educación, y escribió algo que después pasó a ser la segunda parte del libro de los años 50, Gestalt Teraphy: Excitement and Growth in the Human Personality (1951). Con el paso de los años, Fritz llego a hastiarse de la teoría, de la terapia y de Nueva York; se fue al Japón, se fue a Israel, pensado que se iba hacer pintor, y terminó redescubriendo la terapia. Volvió a Estados Unidos, a California, y allá se desconectó de la gente que lo rodeaba los primeros tiempos; en California lo reconocieron como maes- tro, sin necesidad de ponerlo en palabras, había una relación de gran respeto, lo trataban como a alguien de quien no se necesitaban explicaciones, y él ya no necesitaba la teoría de aquel libro de los años 50. Fue esa la época en que yo lo conocí. En esa época Esalen ${ }^{1}$, el famoso instituto donde trabajaba y donde yo estaba haciendo un aprendizaje; donde pasé a ser uno de sus tres sucesores; en esa época, el instituto quiso hacer una monografía que explicara qué es la Terapia Gestalt. Se la pidieron al director de Esalen Michael Murphy, se la pidieron a Fritz Perls, y Perls sugirió que me lo pidieran a mí. Así que hice yo una monografía, un librito de pocas páginas que se llamó "Yo y tú aquí y ahora" en el que quise reducirlo a unas pocas explicaciones y contesté la pregunta que estas haciéndome. Pero la contesté diciendo más lo que yo había visto que Perls hacía. Entonces dije que en la Terapia Gestalt uno de los principios es la vivencia del presente, pero también cuando uno está en el presente se ve que vienen los fantasmas del pasado a presentarse en el presente, $y$ en ese caso se usa en la terapia el intento de revivir el pasado no de recordar el pasado, como la asociación libre, entonces lo que se hace es trasladarse al pasado para dramatizar el pasado: la técnica de la dramatización. Y bueno, escribí una serie de cosas incluyendo el trabajo de los sueños, tomando el sueño como un mensaje existencial (Naranjo, 1968, 2007). Y le gustó muchísimo a Perls; sintió que por primera vez alguien había puesto en el papel algo que correspondía a su manera de hacer terapia, y con respecto a la terapia antigua se me hizo claro a mí porque él ya no hablaba de ella, y porque esto le gustó tanto. Yo conocí el libro antiguo, el libro de los años cincuenta, cuando estaba en Chile, y nunca me habría imaginado a Perls a partir del libro antiguo, ni me hubiera imaginado la práctica de la

\footnotetext{
1 Fundado por Michael Murphy y Dick Price en 1962, en Big Sur California, el instituto se convirtió rápidamente en un punto de convergencia de diferentes áreas y corrientes de la filosofía oriental y occidental, la religión, la psicología, y otras disciplinas, que terminaron por impulsar el movimiento del potencial humano. Entre muchas otras personalidades, allí trabajaron Fritz Perls, Virginia Satir, Aldous Huxley, Alan Watts, Carlos Castaneda, Abraham Maslow, Carl Rogers, Rollo May, Claudio Naranjo, Gregory Bateson, Deepak Chopra, Linus Pauling,
} 
Gestalt. Entonces, cuando escribí sobre Gestalt en respuesta a este pedido de Esalen, lo hice desde lo que yo veía y eso era mucho más coherente, y así lo sintió él. En un momento. Incluso, hice una especie de decálogo sobre la Gestalt incluyendo no solo el aquí y ahora, incluyendo el evitar teorizar y mirar las cosas sin juicio; que el terapeuta no interpreta tanto como que pide la expresión de lo que está pasando; el mayor componente de confrontación, cosas así (Naranjo, 1970).

Pero cuando me tocó escribir un libro poco después, también por sugerencia del mismo Perls, escribí el libro La Vieja y novísima Gestalt. actitud y práctica de un experiencialismo ateórico (editado en español en 1990), quise señalar que el espíritu de la Gestalt era trabajar con la experiencia, con el mínimo de interposición teórica, de forma semejante a lo que es el Zen entre las corrientes espirituales; el Zen no se pierde mucho en palabras tampoco. Lo que yo resaltaría es la pretensión que incluso ya estaba en el existencialismo: el que hay que ir directamente a las cosas, a los fenómenos y las experiencias, pero el existencialismo habla muchísimo de esa pretensión de no hablar, en cambio la Gestalt es más real.

- I R C: iY en ese sentido, qué vendría a ser la salud y la enfermedad en Terapia Gestalt?

Claudio Naranjo: Por una parte, está la idea de que la salud es la persona entera, el funcionamiento integrado de la persona. Por otra parte, Perls veía el Ego como una función de interferencia. La salud es lo que él llamaba la autorregulación organísmica, algo parecido a los que los chinos llaman la función sana, en donde el mecanismo de la mente sabe encaminarse hacia lo que necesita, sabe buscar su dirección, sabe adaptarse, y que normalmente es interferido por un exceso de control de la mente racional. Está también la misma idea freudiana de las vicisitudes de los instintos, de que la vida instintiva está excesivamente reprimida, domesticada. Un poco humorísticamente Fritz toma el superego freudiano y lo transforma en lo que se llama Top dog (Perls, 1969, 1998), el opresor, el mandón interno, así que se intuye que hay la idea que uno pudiera vivir sin un superyó, por lo menos sin un superyó disociado, que es como un cuerpo extraño que uno tiene en la mente como resultado de una introyección obligada de una autoridad parental. Está muy presente la idea de la espontaneidad, o de una integración entre la espontaneidad y lo deliberado, que se acerca a la idea taoísta de la persona sana, espontánea, que no tiene que analizar mucho para actuar, y vive principalmente en el presente, sin excesivo cálculo del día de mañana.

- I R C: iEs decir, que el organismo es una entidad que sabe lo que quiere y que en ocasiones encuentra bloqueo desde la mente?

Claudio Naranjo: Sí, como que el organismo sabe lo que quiere y la mente analítica nunca podría tener la complejidad para competir con la riqueza y la complejidad organísmica. Y lo mejor de la vida viene como en el arte, viene como hecho desde la profundidad, es decir, la persona se autointerfiere demasiado al querer hacer las cosas desde su mente pequeña.

- I R C: iY el proceso terapéutico es procurar la consciencia de cómo son esos bloqueos, para paulatinamente distanciarse de ellos, o verlos más de relieve y tener más opciones sobre cómo actuar sin bloquear la autorregulación?

Claudio Naranjo: El énfasis de la terapia es la atención a lo que ocurre aquí y ahora, para poder verle la cara alguno de los fantasmas, o verle la cara a alguno de los supuestos erróneos que uno vive, para poder confiar más, para ir quitándose el policía interno desde el cual se vive, y poder ir experimentando con la vida, ir dándose cuenta que uno no necesita un régimen policial, que uno es bueno no por un sistema represivo, artificial, y que la naturaleza es algo en que podemos confiarnos y no como se pensaba en tiempos de Freud, una animalidad destructiva y peligrosa (Freud, 1930/1993).

- I R C: Nombrabas ahora el Top dog, el opresor, al que se le antepone la polaridad del Under dog, el oprimido. Algo que fue muy significativo como aporte de la Terapia Gestalt fue la idea de 
polaridad. Tomar dos elementos de la persona, que son supuestamente antagónicos, e integrarlos para experimentar un ser más pleno (Perls, 1942/2007).

Claudio Naranjo: Sí, gran parte del trabajo terapéutico de Fritz era integrar polaridades. Trabajase en lo que se trabajara, siempre veía alguna polaridad, una polaridad entre el niño bueno y el rebelde; una polaridad entre la parte tierna y la violenta; toda clase de personajes contrastantes presentes en la acción del momento, en el conflicto del momento, y su actividad era tratar de ayudar a esa integración.

- IR C: ¿Cómo entiende entonces la Terapia Gestalt al ser, a la persona?

Claudio Naranjo: La persona es aquello en que se integran las polaridades. Así Perls lo dice en un artículo. Dice que a él no le gusta usar el Self, la palabra self (con mayúsculas), ya que no quiere transformarlo en una entidad semidivina, como Jung, simplemente es el lugar de encuentro de las polaridades, o sea, el todo de la persona, la persona que resulta de la integración. La fragmentación es parte de la neurosis, la neurosis es una fragmentación.

¿Qué es la persona? Yo diría que la persona para él es el equivalente al aquí y ahora. No le gustaba mucho destilar que en la persona hay un yo diferente de la experiencia. La persona y su experiencia son la misma cosa. El yo es el campo de la consciencia. El yo es el flujo de la experiencia. Es cierto que escribió un libro que se llama Ego, Hambre y Agresión (1942/2007); él usaba la palabra ego en un sentido más ligado a los mecanismos de defensa, a una función de interferencia con el organismo. Tomó más ese sentido de elemento neurótico que el elemento positivo que tomaron los psicólogos del ego, en la psicología inglesa sobre todo.

Pero aunque se puede hablar de los presupuestos teóricos de Perls, que muchos fueron modificaciones de los presupuestos teóricos del Psicoanálisis, había mucho en él que era simplemente chamánico. Muchas veces he citado una frase que él dijo en un taller en que también decía algunas cosas en respuesta a las preguntas que le pedía a cada uno que contestara, él dijo: "tengo ojos y no tengo miedo", y yo muchas veces he dicho que ese es el presupuesto teórico fundamental de la Gestalt. ¿Por qué funciona la Terapia Gestalt? Porque el terapeuta entiende lo que está pasando y no tiene miedo de actuar según lo que ve. Si ve que el otro está haciendo un juego ridículo consigo mismo, el terapeuta lo ve como en caricatura, desde su salud, y es capaz, por último, de reírse. Ya basta con que lo perciba y tenga la capacidad de exponerlo, eso tiene un efecto transformador, eso crea consciencia. ¿Por qué veía él tanto? Por su propio desarrollo, porque había llegado a cierta realización. Cuando venía gente a verlo trabajar, en el periodo de Esalen, venían de todas partes del país, después empezaron a venir de Europa también, como se viene a ver a un brujo, a un milagrero que hace cosas nunca vistas; se veía que entraba una persona y salía profundamente afectada, con una visión diferente de las cosas, o por lo menos muy conmovida y, así, una y otra vez. En las sesiones psicoanalíticas de aquella época la gente entraba y salía igualita; por mucho que se hablara, había que buscar a ver para qué sirvió la sesión. No era muy claro. Yo tenía mi oficina al lado del Mental Health Institute, el estamento de salud mental en Washington; estábamos en California pero teníamos oficinas vecinas y estábamos ambos visitando el Instituto de Estudios de la Personalidad. Me decía que había invertido en grandes cantidades de film de sesiones terapéuticas psicoanalíticas buscando los momentos terapéuticos y el resultado fue muy pobre, y eso al lado del trabajo de Fritz, se veía a una distancia tan abismal. Después los gestaltistas han querido reescribir la historia de la Gestalt y han pretendido que Fritz no hacía terapia, cuando estaba en California, una cosa absurda, decían que lo que él hacía eran demostraciones. Como queriendo hacer desaparecer todo lo que hizo, y lo que hizo fue extraordinario. La gente aprendía algo de verlo trabajar. Yo aprendí Gestalt de verlo hacer Gestalt; aprendí de la Gestalt que recibía en mi cuerpo y que lo vi hacer en otros. Después quisieron los que lo sucedieron hacer cursos de Gestalt con mucha teoría, quisieron hablar mucho de Gestalt, pero generalmente perdieron la capacidad de hacer el tipo de Gestalt que hacía Perls. 
- I R C: Eso te iba a preguntar ¿Cómo llega un terapeuta a ser terapeuta gestáltico y a lograr esa actitud donde no tiene miedo de actuar sobre lo que nota, lo que percibe?

Claudio Naranjo: En Fritz no había una distinción neta entre vivir el proceso terapéutico y aprender a hacer terapia. Se aprende viviéndolo. En el Psicoanálisis ya estaba presente esta idea. El psicoanálisis didáctico, no es un psicoanálisis didáctico, es un psicoanálisis en un contexto en que la persona está en formación y se supone que esto le va a servir para aprender hacer psicoanálisis, pero el Psicoanálisis es Psicoanálisis; así que cuando Fritz organizaba cursos para profesionales, eran cursos de profesionales por quienes asistían a él, ya que se dejaba entrar solamente a la gente que ya era profesional, pero no porque diera muchas más explicaciones, tal vez un poquito. Se podían hacer preguntas, se discurría un poco, pero no había tal cosa como teoría.

- I R C: Ya desde los inicios en Esalen, y lo que nos has venido compartiendo, había algo que la Gestalt tenía muy cercano a lo espiritual. Y tú has dicho en el SAT ${ }^{2}$ que la Gestalt es el Zen de las psicoterapias y el Zen es la Gestalt de las religiones.

Claudio Naranjo: Eso lo he dicho para comparar a ambos por su carácter de experiencialismo, por su manera de ir directamente a trabajar con la experiencia y hacer crecer a la persona con el mínimo de explicaciones.

Con respecto a que fuera espiritual, habría dos cosas que decir que son igualmente ciertas. Fritz no era muy amigo de una forma espiritual tradicional. El fue a Japón y visitó un templo Zen; tenía una atracción por el Zen y cuando vio que el maestro Zen se inclinaba ante un Bodhisattva, ante una escultura de Bodhisattva y le quemaba incienso, se sintió decepcionado porque él buscaba una religión sin Dios. A él le chocaba lo devocional. Puede que ésta haya sido una limitación de él. Cuando se tra- taba de una espiritualidad más cristiana o el hinduismo, por ejemplo, sentía Fritz que eso era entrar en mundos simbólicos, en mundos dogmáticos, llenos de hipótesis sobre el más allá que no lo atraían. Lo que le atraía a él era la plenitud de la experiencia en el presente. Sin embargo, yo creo que se parece en mucho la Gestalt al Budismo, en varias fases del Budismo. El aquí y ahora es muy parecido a la meditación Budista, al camino, al método de percatarse de lo que está pasando, lo que es el punto de apoyo para todo lo demás. Y en el Budismo tántrico, en el Budismo tibetano, hay lo que se llama las enseñanzas de la gran perfección que tienen un sabor muy parecido a la Gestalt. Lo que hay más de espiritual en la Gestalt es la neutralidad. En otros términos, se puede decir el desapego. A mí me costó tomar consciencia del despago de Fritz, porque él no usa ese lenguaje y más bien éste estaba en su actitud como una forma de desdramatizar las cosas; cuando, por ejemplo, el paciente estaba llorando por tal asunto muy doloroso del pasado, Fritz podía en un momento decir " ¿...y cuánto más va a llorar sobre tu pasado?" Como quien pone en ridículo la decisión implícita de la persona de estar lamentándose ahora de algo que fue y no pudo haber sido de otra manera; como llamándole la atención al otro a la libertad de ser alguien diferente, de tomar una actitud diferente. $Y$ a veces las palabras que usaba para inducir esa actitud sanadora, más saludable era "iy qué?... iy qué?" (iSo what?). Como que en el "iy qué?" estaba un "déjate de tragedias, deja de hacer ruido sobre eso, isuéltalo!, iDéjalo pasar!” Cuando él decía awareness, la palabra para toma de consciencia, no era simplemente tomar consciencia de un proceso que ocurre en la sombra, el darle luz a eso hace que se tome una decisión más clara, una actitud más clara. Había también la idea de que si uno es consciente, uno es consciencia. Había un llamado a que uno se identificara con la propia consciencia y la consciencia no toma partido, y no es nada más que una fuerza con la que uno se puede anclar en esa presencia, había un sentido de lo saludable de la presencia, de que la presencia misma es sanadora.

2 SAT III realizado en Bogotá, en el mes de Abril de 2010. 
- IR C: Y a eso te refieres con neutralidad, que la consciencia no toma partido.

Claudio Naranjo: Exactamente. Estar aquí y ahora es estar en la neutralidad y eso también contribuye a la capacidad de síntesis, a la capacidad de integración de los opuestos.

- I R C: Pareciera que la forma en que la Terapia Gestalt fue entonces concebida, la forma de trabajo, es la base para muchos otros enfoques o aportaciones de disciplinas diferentes, o de áreas diferentes, y en tu trabajo sí que se nota eso. Por ejemplo, el estudio del carácter a través del Eneagrama ${ }^{3}$ o la misma meditación. Quiero saber, por ejemplo, icómo integras el Eneagrama, la meditación, a tu forma de trabajo y a la Gestalt de por sí?

Claudio Naranjo: Comencemos con la meditación. Fritz decía que él meditaba todos los días. Es un argumento de que había una espiritualidad viva en él. Pero iqué quería decir con que meditaba todos los días? Quería decir que practicaba el estar en el presente. Vivir atentamente. También quería decir que más y más en sus años de vejez, apreciaba la entrega, el disolverse, el soltar la voluntad de control sobre sí mismo: esas dos cosas para él eran meditar. Por otra parte, yo recuerdo una vez un teólogo que estaba haciendo una sesión con él y que usó la palabra Dios en la sesión, y Fritz le dijo: "tu Dios se interpone entre tú y yo", como diciéndole aquí y ahora estás tú y estoy yo, y estás metiendo a este Dios como algo que complica esta relación, como una idea que complica la relación. Entonces sí, la meditación es muy coherente con la Gestalt. Es una forma de estar en el presente, una forma de estar abierto, una forma de práctica de una actitud sana también se puede decir. Con respecto al carácter,

3 Tradición Sarmouni que trata sobre la naturaleza y el ser humano. Esta tradición llega al mundo occidental, a principios del siglo XX, a través de George I. Gurdjief, y a América a través de Oscar Ichazo y Claudio Naranjo, quien a partir de sus enseñanzas, ha elaborado una perspectiva integradora de los tipos y modelos psicológicos de la personalidad.
Fritz tenía muchas versiones, muchas veces tomadas del lenguaje popular; "estas haciéndote el idiota" le podía decir a alguien; usaba un poco el lenguaje de Eric Berne quien escribió el libro Games people play (Juegos que hace la gente) donde habla sobre distintos patrones relacionales, grotescos a veces, en fin neuróticos (Berne, 1964/1986). Y entonces Fritz a veces tenía muy clara la percepción también del carácter. Recuerdo una vez a una mujer que, desde nuestros ojos, yo la llamaría una cuatro-competitiva, una cuatro-sexual, donde la envidia competitiva es muy impermeable a las intervenciones del terapeuta porque pretende saber más. Entonces, hubo varias veces que la mujer saboteó alguna intervención de él, y Fritz le dice "No tengo muchas ganas de seguir trabajando contigo, iA cuántos terapeutas has derrotado en el pasado?" Entonces, había una gran consciencia del carácter. Una vez hablando con él usó una frase "más sabe el diablo por viejo que por diablo", en el sentido en que ese conocimiento del carácter viene de haber vivido lo suficiente, de haber visto repetirse los patrones que la gente hacía en el pasado. Si yo le hubiera explicado el Eneagrama, que no llegó a darse el caso, porque cuando yo conocí esa caracterología ya había muerto él...

- I R C: Él ya había muerto, pero ialcanzó Perls a leer algo sobre el Eneagrama, lo conoció?

Claudio Naranjo: No, no lo conoció. Yo pienso que si le hubiera mostrado eso, puede que le hubiera parecido normal, que sí, que la gente es así, pero pudiera también haber simpatizado con la actitud de que no se necesita saber tanta cosa, porque si tú trabajas en el presente, con lo que hay, siempre se te va abrir la vena de lo que necesitas entender, porque está a la vista. Si alguien está escondiéndose, si alguien está yéndose para adentro, no saliendo al encuentro, es un esquizoide. Él lo vería obviamente porque está ahí, y no se necesita un mapa para decirle a la persona "tú no me estás saliendo al encuentro", o para decirle a otro que está queriendo entretener al terapeuta con muchas palabras, o lucirse. Él hubiera visto el siete sin necesidad de 
saber que es siete ${ }^{4}$, así que para alguien que tiene una mirada despejada pudiera ser ésta una muletilla innecesaria. Y algunos gestaltistas, después cuando hablé sobre el Eneagrama, tomaron una posición así. Que la Gestalt debe ser fenomenológica, atenerse a lo que hay y al intento de no estar con ideas postizas. Pero una excepción a eso han sido los reichianos. Ha habido bastante reichianos gestaltistas que han hecho esa síntesis, que han combinado cosas, y según ellos les ha servido mucho el concepto de que la persona es oral o rígida, porque sirve para extrapolar. Si a la persona yo le veo tales o cuales conductas, yo puedo predecir algunas características, entonces uno según eso, puede proponer un trabajo; también hay antídotos. Recuerdo un terapeuta bioenergetista norteamericano que pensaba que a los esquizoides, por ejemplo, hay que invitarlos a que se disuelvan. Entonces proponía una imaginería, una visualización, y así para cada uno de los tipos de bioenergética proponía algún ejercicio terapéutico imaginativo. Aún así, hay una tendencia demasiado dogmática cuando la gente quiere ser tan fiel a la Gestalt que no toman nada prestado; la tendencia de Laura Perls era así. Sí hay trabajo corporal, pero esto de tener Gestalt y trabajo corporal, ya eso a ella se le hacía innecesario porque tomaba, tal vez arrogantemente, una posición en la que como gestaltista quizá use el trabajo corporal como parte de la sesión cuando viene al caso, y no le gustaba la idea que la persona esté haciendo Gestalt y esté yendo a un grupo de terapia corporal como un complemento. Ésta me parece que es un poco la tendencia de tantas escuelas desde religiosas hasta disciplinas académicas, lo que es una cosa territorial. Tiene perfecto sentido que una persona haga Gestalt y tenga alguna formación en Tai Chi por ejemplo; una cosa no puede remplazar a la otra, solo se agregan los frutos de dos disciplinas, cada una con su historia y con sus métodos.

4 Eneatipo siete.
- I R C: No permitirlo es segregar, dividir...

Claudio Naranjo: Sí, es como decir iYo lo tengo todo, con la Gestalt basta!

- IR C: ¿Se puede decir que hay una Gestalt pura o algo semejante, y hay una Gestalt integrativa?

Claudio Naranjo: Bueno, yo usé esa palabra, Gestalt integrativa, aunque para Perls la Gestalt es integrativa; él era una persona que tomaba de aquí y de allá, y lo que iba haciendo siempre estaba al día con las ultimas cosas que había conocido, y las metía en su manera de hacer terapia. Pero a veces, para los seguidores de Fritz, había que dejar pura la síntesis que él hizo, y no aprendieron de él la actitud de seguir dejando que la Gestalt creciera.

- I R C: Lo cual es lo más básico, la actitud, no la tomaron por completo, por así decirlo.

Claudio Naranjo: Es como el patriotismo, yo creo que es un fenómeno casi político decir ésta es la Gestalt, nosotros somos gestaltistas, esas son personas que están improvisando, personas que no tienen nuestra aprobación, y nosotros hacemos la Gestalt correcta y decimos quien es buen gestaltista y quien no; nosotros damos crédito. Éstas son máquinas de poder que operan en el mundo académico.

- I R C: ¿Y cómo crees tú que es la actualidad de la Terapia Gestalt?

Claudio Naranjo: Yo creo que está muy diluida hoy en día. Cuando escribí un libro al que llamé Por una Gestalt viva (2007), en el prólogo explico que no necesitaría decir Gestalt viva, porque la Gestalt es viva, pero uso este título porque hay también una Gestalt muerta, porque hay una Gestalt imitativa, rígida, dogmática, excesivamente teórica, lo cual es el fruto de que la Gestalt cayó en manos de gente que no tenía mucho poder terapéutico. Lo que pasa es que los colaboradores de Fritz, de Nueva York, cuando Fritz se fue a Esalen, simplemente dejaron de hacer Gestalt; ellos tenían una Gestalt débil que en la presencia de Fritz sobrevivía; había un insti- 
tuto de Gestalt fuerte en Nueva York. Y después cuando se retiró Fritz, y se fue a California, no se oía hablar de esa gente, ellos no hacían olitas en el mundo de la terapia. Cuando muere Fritz, hubo un gesto político de apoderarse ellos de la Gestalt, en donde se hicieron presentes diciendo que eran los más antiguos, que eran las autoridades, y viendo que la Gestalt era importante en el mundo, se pusieron al centro de la Gestalt, constituyeron la revista, centralizaron el congreso de Gestalt, y a través de ese gesto de ponerse al centro le quitaron a la Gestalt sus alas, le quitaron su plasticidad, le quitaron su libertad. Fritz nunca había querido encajonar a la Gestalt en una definición, o decir ésta es la Gestalt verdadera; ni siquiera le interesaba la acreditación de los gestaltistas. "Allá se verá, los que son buenos harán camino, los que no, no tendrán discípulos, no harán escuela", decía. Él confiaba en el proceso orgánico. Entonces la gente que no tenía tanta fuerza terapéutica como los que trabajaron con Fritz en su época de mayor madurez, cuando el completó su propio viaje, cuando se hizo maestro; los que lo habían acompañado en una época relativamente inmadura de su desarrollo profesional, cuando ellos se pusieron al centro tuvieron que ir llenado con teoría lo que les faltaba de vitalidad terapéutica. Yo estuve en el Congreso Internacional de Gestalt en Córdoba ${ }^{5}$ hace algunos años. Me dieron la charla inaugural, dije cosas que no le gustaron a los organizadores, aplaudió mucho el público, pero los organizadores quisieron borrar eso y me dicen que ni siquiera me mencionaron en la sesión final de evaluación, a pesar de que se venía abajo el edificio con la fuerza de los aplausos del público, quisieron los organizadores decir aquí no paso nada, porque se veía amenazado el prestigio de unos franceses que ellos exaltan mucho, que tienen cosas finas que decir, pero se ve que se quiere llenar con teorías algo que no es propiamente Gestalt, como un intelectualismo, hay mucho de eso. La Gestalt no es un movimiento que ha crecido, la Gestalt es un movimiento que históricamente se ha deteriorado,

5 X Congreso Internacional de Gestalt y el III Latino en Villa Giardino, Córdoba, Argentina, Mayo 2007. se ha esparcido en el mundo, pero a medida que ha ganado terreno ha ido vendiéndose la Gestalt a la buena educación, a la buena forma académica, a cosas que le quitan algo de su empuje original.

- I R C: Que le quitan potencia.

Claudio Naranjo: Potencia, sí.

- IR C: Al principio decías que Fritz tenía algo de chamán, y continuamente hablas de la terapia y de la relación terapéutica, y de la actitud no solo gestáltica sino también unida a otras áreas, como una actitud de un neochamanismo. ¿Qué quieres decir con eso?

Claudio Naranjo: A ver, yo, en primer lugar, conocí a Fritz en un taller que hice con Castaneda en Esalen, siendo él parte del público. En uno de los intervalos, vi que estaba rodeado por un grupo de gente que lo escuchaba comentar sobre una indígena chamana norteamericana a la que habíamos escuchado, y básicamente Fritz estaba diciendo "Pero si ella es chamana, yo también soy chamán". Él se identificó como chamán. "¿Acaso no les pasa a ustedes que se guían por sus intuiciones, o no les pasa a ustedes que a veces a uno le viene una imagen que lo guía para saber cómo intervenir". Y eso me puso sobre la pista de la actividad chamánica de Fritz. Pero quiero decir con neochamanismo que no debemos quedarnos tan presos de las definiciones formales del chamanismo, como que el chamán le da mucha importancia al tambor, o que el chamán tiene un animal de poder. Lo básico del chamanismo es que actúa en forma creativa, que actúa desde la intuición. Sí, se puede decir que la intuición está más desarrollada que una persona corriente; se puede llegar a decir que el chamán es un visionario que tiene intuiciones muy potentes. Y Fritz tenía eso, Fritz veía lo que pasaba en la gente más allá que un terapeuta intuitivo ordinario. Yo creo que tenía una buena dosis de clarividencia y no se jactaba de ella y la usaba como un recurso invisible. Era chamánico también en el sentido en que hay algo entre el chamán y el instinto. Mircea Eliade habla del chamanismo y el fuego interior, como un maes- 
tro del fuego, y lo explica de forma relacionada con ciertas técnicas o rituales que tienen que ver con el mundo de la kundalini, que es el mundo del cerebro primitivo, el mundo del cerebro reptiliano, que es básicamente el mundo del dejarse ir (Eliade, 2001, 2007); podría decir, también, el mundo de lo dionisiaco, y el chamán es aquel que cree en la entrega, por eso está tan cercano al mundo del chamanismo, el mundo de ciertas drogas en que se desasen los controles habituales de la mente y se entrega la mente a un flujo que tiene su organización propia más profunda, la sabiduría organísmica. Todo esto estaba muy presente en el sentir de Fritz. Él se interesó también en los psicotrópicos, se interesó ya en tiempos en que nos conocimos. No quiero decir mucho más, no quiero complicar la cosa con esto de chamanismo, solo quiero plantear que la forma de terapia que él proponía era hacer terapia desde la intuición y desde la vida, la experiencia de vida, sin pasar por tantos presupuestos y por elaboraciones teóricas preestablecidas. Hay gente que le tiene mucho miedo a eso; le tiene miedo también a la figura carismática del terapeuta. Recuerdo una historiadora de la medicina que me entrevistó, para una revista española, que decía "Pero ino es peligroso eso que el terapeuta tenga que ser alguien tan especial? Entonces ien qué queda la terapia de los demás? Hay que tener principios para que todos puedan acceder". Entonces como que querrían borrar la figura del genio terapéutico, para que quede solo la terapia de los mediocres. Como que les hace sentirse bien a los académicos y a las psicoterapias que han aprendido con libros, el suponer que lo otro no está bien; algo así como invalidar en lugar de tomarlo como modelo y decir "hay una forma de hacer terapia que viene más desde dentro y desde la experiencia y sería bueno que nosotros llegáramos a conocerla, a aprenderla, y no tener que hacer las cosas siempre por libro".

\section{Referencias}

Berne, E. (1986). Juegos en que participamos (18 a ed.). (P. Escalante, Trad.). México: Editorial Diana S.A. (Trabajo original publicado en 1964)

Eliade, M. (2001). El chamanismo y las técnicas arcaicas del éxtasis. Madrid: Fondo de Cultura Económica.

Eliade, M. (2007). Nacimiento y renacimiento. El significado de la iniciación en la cultura humana (2a ed.). Barcelona: Kairós.

Freud, S. (1993). El malestar en la cultura. En J. Strachey (Ed.) y J. L Etcheverry \& L. Wolfson (Trads.). Obras completas. (Vol. 21). Buenos Aires: Amorrortu. (Trabajo original publicado en 1930)

Naranjo, C. (1968). I and thou, here and now: Contributions of Gestalt Therapy (Paper No 5.). Big Sur, CA: Esalen.

Naranjo, C. (1970). Present-centeredness: Technique, prescription, and ideal. En J. Fagan \& I. Shepard (Eds.), Gestalt Therapy now. New York: Science and Behavior Books.

Naranjo, C. (1990). La vieja y novísima Gestalt. Actitudy práctica de un experiencialismo ateórico. Santiago de Chile: Cuatro Vientos.

Naranjo, C. (2007). Por una Gestalt viva. Madrid: La Llave D.H.

Naranjo, C. (2007). Yo y tú, aquí y ahora. En C. Naranjo (Ed.), Por una Gestalt viva (pp. 56-75). Madrid: La Llave D.H.

Perls, F. (1969). Gestalt Therapy Verbatim. Moab, UT: Real People Press.

Perls, F. (1998). Sueños y existencia (12a ed.). Santiago de Chile: Cuatro Vientos.

Perls, F. (2007). Yo, hambre y agresión: Una revisión de la teoría y del método de Freud. (C. Vázquez, Trad.). Madrid: Esquio-Ferrol. (Trabajo original publicado en 1942)

Perls, F., Hefferline, R. \& Goodman, P. (1951). Gestalt Therapy: Excitement and growth in the human personality. New York, NY: Julian. 